\section{Optimizing Light Microscopy for Biological and Clinical Laboratories}

by Barbara Foster

Kendall-Hunt Publishing, Dubuque, lowa

187 pp, (1997) ISBN 0-7872-3538-5

Reviewed by A. G. Moss

Auburn University, Zoology Dept, Auburn, Alabama.

Modern microscopy allows the life scientist to produce seductively beautiful images with powerful techniques developed by brilliant physical optical scientists, and yet be nearly completely confused with regard to the importance of the results. This is because modern microscopes are something like Lotus race cars: they have all the performance to fly in the hands of an experienced user, or crash and burn spectacularly in the hands of a novice. There is therefore great need for a comprehensive and accurate but accessible "drivers manual" for modern microscopical techniques.

Barbara Foster has provided such a text. In Optimizing Light Microscopy, she has found a way to take the novice user from a useful, very direct and non-intimidating introduction through polarized light microscopy, differential interference and fluorescence. Additional advanced techniques such as digital image processing and a comparison of atomic force and electron microscopical techniques are presented. Experienced users will also no doubt gain from this text, which assumes nothing about the reader's background, but nevertheless takes the reader to a fairly high level of competency.

This is an extraordinary book in that it very effectively bridges theory and practical application. A quick tour of the contents is very revealing: In Chapter 1, "Laying the Foundation", Foster discusses light/matter interactions and the basic physics underlying the behavior of light in different media and different materials. This is followed by a clear, understandable explanation of optical terminology and the relationship to the microscope. In Chapter 2, "Geometric Optics and Alignment (How does your microscope work?)", which ends with a discussion of the all-important Köhler illumination method and the use of the conjugate planes to adjust the microscope properly.

In Chapter 3, "Pushing the Limits of Resolution", she describes the theory of development of resolution and contrast in the microscope and the relationship to the image. "Some Practical Microscopy", Chapter 4, is critically important and full of practical advice for the recognition of different optics and their properties, and ends with a brief set of tips for the buyer to effectively match purchase with application. Chapter 5, "Bringing Out the Best", refers to different modes of obtaining improved contrast in the final image. Here, as elsewhere throughout the text, Foster encourages the reader to try little experiments to test the function of the microscope components and demonstrate how they can be adjusted. The proposed exercises here, however, are priceless, and it is here where Optimizing Light Microscopy is at its best. The next two chapters, 6 and 7 "Contrast II: Techniques Using Condenser plus Objective", (discussion of phase and Hoffmann modulation contrast) and "Contrast III: Advanced Techniques (Fluorescence, Polarized Light, and DIC)", are exactly what the professional user of any of these techniques will find at first very informative and then a useful reference as he or she goes about the daily effort. Foster might here have included an expanded version of her section on confocal microscopy, since it has become so very much more popular in recent years.
In subsequent chapters, Foster moves away from the more arcane aspects of microscopy and deals with the practical collection of data. "Basic Measurement", Chapter 8 , deals with the sim- $\dot{\vec{o}}$ ple problem of size measurement using first conventional calibration with optical and stage micrometers, and then reference to computerized collection techniques. Chapter 9 deals with $\overrightarrow{\tilde{N}}$ "Archiving and Documentation" and discusses the advantages of " conventional versus digital means of saving your images. Fostero deals with "old-fashioned" photographic technique (not to say that silver-based photography is bad or outdated; just the opposite!). $\frac{.}{\sigma}$ She deals effectively with such little-examined topics (at least for $\frac{\overline{\bar{n}}}{\bar{\pi}}$ most modern biology students) as darkroom technique, reciproc- $\frac{0}{\circ}$ ity, and exposure calibration. She also discusses the characteris-产 tics of digital imaging with CCD cameras, and storage of large 0 digital images. She quite correctly defers to local representatives $\frac{\varrho}{3}$ for answers to digital printing and long-term archiving, since these흠. technologies change significantly every few months.

In Chapter 10, "What's Next?", she discusses selected "power user" techniques such as digital image analysis, spectro- $\frac{\Phi}{\text { s. }}$ photometry, interferometry, confocal imaging, and scanning probe and electron microscopy.

In some ways my favorite parts of the book, however, are the very useful Appendices, which cover the history of microscopes, various optical abberations and various microscopy troubleshooting issues, an all-in-one summary of contrast-enhancement, and an outstanding glossary. Foster ends the appendices with a table of filter sets for fluorescence, (quite possibly the most common type of questions I encounter). A list of equations (Appendix $G$ ) will probably be used by only the most dedicated microscopists, but the list of vendors in the back (Append. H) will be more than enough to get the new microscopist, or the experienced investigator setting up his/her lab for the first time, off to a strong start.

Foster's approach is excellent. She has a friendly style of writing and tries to directly engage the reader/user in miniexperiments. Each chapter contains quizzes designed to expand the users' skill, and she provides useful, succinct summaries of each of the chapters. The book needs an index and it would help to make the book even more useful.

This is an excellent manual for an upper level dedicated course for undergraduates, or a graduate/technical training level course. It should be on the bookself of every microscopist and every microscopy facility. It will be very useful for new graduate students and skilled users alike.

\section{To Order (Cost: $\$ 37.00$ plus $\$ 4.75$ U.S. S\&H)}

From Internet: visit: Www.MME-Microscopy.com/education and follow the links to the book.

Direct: write, call, fax, or email Ken Piel as follows:

Microscopy/Microscopy Education

125 Paridon St., Ste 102

Springfield, MA 01118

Tel.: (413)746-6931

Fax: (413)746-9311

eMail: kenpiel@map.com

Discounts are available for class-sized orders (min. 10) and, with two book orders, there is no S\&H for the second book.

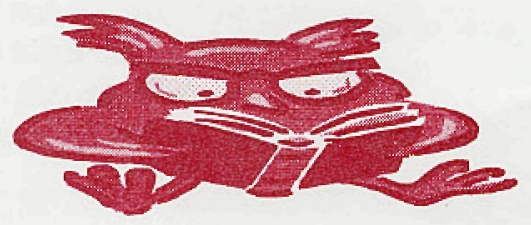




\section{GOMInG avenis}

$\checkmark$ LEHIGH MICROSCOPY SCHOOL, Bethlehem, PA

June 14/18 ' 99 : SEM and X-ray Microanalysis

June 13 '99: Introduction to SEM and EDS

June 21/25 "99: Advanced Scanning Electron Microscopy

June 21/25 "99: Quantitative X-ray Microanalysis

June 21/24 "99: Analytical Electron Microscopy

June 22/25 '99: Atomic Force Microscopy

June 21/24 ' 99 : Microdiffraction

Info: Ms Sharon Coe: (610)758-5133, email: slc6@lehigh.edu

http://wwww.lehigh.edu/ inmatsci/shortcourse/Microacourses.htm|

$\checkmark$ June 16/27 '99: 3D Microscopy of Living Cells \& June 29/July1 '99: 3D Image Processing Workshop (Univ of British Columbia) Vancouver, $\mathrm{BC}$ Canada. Prof. James Pawley: (608)263-3147, jbpawley@facstaff.wisc.edu

$\checkmark$ June 20/25 ' 99 : Fundamentals and Applications of Light Microscopy (McCamnn Imaging) Wellesley, MA (617)484-7865, mocanns@tiac.net

$\checkmark \quad$ June 21/25 '99: Electronic Image Acquisition, Processing \& Analysis (McCrone Research Institute) Chicago, IL. Nancy Daerr: (312)842-7100, Fax (312)842-1078, eMail: ndaerr@mcri.org

$\checkmark$ June 21/25 '99: 15th Annual Short Course on Molecular Micro. spectroscopy (Miami Universtiy) Oxford, $\mathrm{OH}$ (513)529-2874, fax: (513)5297284, email: http://Www.muohio.edu/ -sommeraj

$\checkmark$ June 21/25 '99: Fourth Annual Fundametals and Applications of Light Microscopy. (McCann Imaging/Wellsey College) Wellsey MA. Mary McCann (617)484-7865, Fax: (617)484-2490, www.microscopyed.com

$\checkmark$ June 25/July 1 '99: INTER/MICRO '99 (McCrone Research Institute), Chicago, IL. Nancy Daerr: (312)842-7105

$\checkmark$ July 9/13 '99: IUMAS 2000: The 2000 Meeting of the International Union of Microbeam Analysis Societies. Kailua-Kona, Hawaii

$\checkmark$ July 19/22 '99: Electron Microprobe Analysis by Wavelength Dispersive Spectroscopy on JEOL JXA-733 Superprobe (MIT) Boston, MA (617)253-1995, e-probe-www@mit.edu

$\checkmark$ Aug 1/5 '99: MICROSCOPY \& MICROANALYSIS '99 (MSA) Portland, OR

$\checkmark$ Aug 9/13 '99: Summer School on Computing in Electron Microscopy (NCEM, Lawrence Berkeley Natl Lab) Berkeley, CA, (510)486-6036, Fax: (510) 486-5888, http://ncem.lbl.gov

$\checkmark$ Aug. 17/19 '99: Imaging Tech. (ASM) Chicago, IL. Derek KJ. Weston, (440)338-5151 X5601, dweston@po.asm-intl.org

$\checkmark$ Aug 24/26 '99: Workshop on Variable Pressure SEM Monttreal, QC, Canada, Dr. Pierre Hovington (450)652-8125, Fax: (450)652-8424

$\checkmark$ Aug 27/29 99: First International Conference On Scanning Probe Microscopy of Polymers. (UCSB \& Digital Instruments). Santa Barbara, CA E. J. Kramer at edkramer@mrl.ucsb.ca

$\checkmark$ September 21/24 99 : Using Ultramicrotomy in Materials Science (Ventana/RMC) Tucson, AZ, Steve Miller: (520)903-9366

$\checkmark$ October 2 '99: 5th California Microscopy Colloquium. (CSU \& NCMS) San Francisco, CA. Http://online.sfsu.edu/ -camicro/

$\checkmark$ October 20/22 '99: Asbestos Analysis by Transmission Electron Microscopy (McCrone Research Institute), Chicago, IL Nancy Daerr: (312)8427100, eMail: ndaerr@mcri.org

$\checkmark$ October 6/14 '99: Optical Microscopy \& Imaging in the Biomedical Sciences (Marine Biological Lab) Wood Hole, MA. Carol Hamel: (508)289-7401, eMail: admissions@mbl.edu

$\checkmark$ October 20-22 '99: Asbestos Analysis by Transmission Electron Microscopy (MVA) Norcross, GA. Nancy Daerr, McCrone Research Institute, (312)842-7100, Fax: (312)842-1078

$\checkmark$ October 22 '99: 5th California Microscopy Colloquium (CA State Universities \& Northern CA Microscopy Society). San Farncisco State University $\mathrm{Http}$ :/online.sfsu edu/ camicrol

$\checkmark$ Nov 14/19 '99: 1999 Eastern Analytical Symposioum. Somerset, NJ. (302)738-6218, eMail: easinfo@aol.com, http://www.eas.org/
WinEDS 3.0 High Performance X-ray Microanalysis For Windows ${ }^{\mathrm{TM}} 95 / \mathrm{NT} 4.0$

This FAST full 32-bit PC Windows ${ }^{\mathrm{TM}}$ based analyzer gives you all the performance of more expensive workstation systems.

X Qualitative \& Quantitative software with one click operation.

X WinEDS PX9000 Pulse Processor DX3000 Bias.

X Interfaces to several detector brands.

X 5 to $10 \mathrm{eV}$ improvement on most detector's resolutions.

X Complete system upgrades - including new detectors.

X Partial upgrades to suit your system needs. Aiso

X Complete line of PC based imaging systems.

$\times$ Top dollar for trade-ins.

X Service for TN5500 and TN2000 systems.

\section{TN Analyzer Service Inc. 7897 Hwy 19 \\ Dane, WI 53529}

Tel.: (608)798-2005, Fax: (608)798-1675, eMail: doug tnas@msn.com

Visit our web site: www.tnanalyzerservice.com Vow with demo labs in Florida and Texas, as well as in Wisconsin - and soon on the west coast.

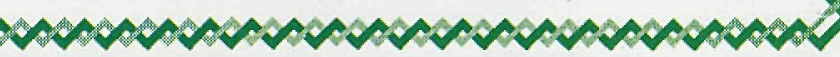

\section{Remove the Veil of Contamination from SEM Samples!}

\section{Flash SEM-CLEAN in-situ Cleaning}

- Quickly remove hydrocarbon scum from SEM chamber walls and samples

- Clean samples in-situ

- Fast - less than 5 minutes

- Activated Oxygen cleaning action

- Safe - No sputter etching

- Ideal for Materials Science and Metrology

- No exotic gases - No Argon

- Patent pending

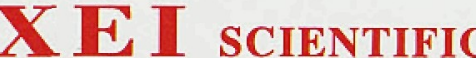
Anti-Contamination Systems for SEMs

3124 Wessex Way, Redwood City, CA 94061 (650) 369-0133, FAX (650) 363-1659

http:/www.msa.microscopy.com/SM/XEI/XEIHomePage.html 